\title{
Identifying and Ranking the Factors Affecting Honoring Customers in the Metropolitan Municipalities - Case Study of Tehran Municipality
}

\author{
Esfandiar Doshman Ziari ${ }^{1}$, Ebrahim Kazemi ${ }^{2}$, Behdad Mirafshar ${ }^{3}$, Amir Rashidi ${ }^{4}$, \\ Vahideh Pourahad $^{5}$ \\ ${ }^{1}$ Department of Management, College of Humanities, Islamic Azad University, Tehran, Iran \\ ${ }^{2}$ Department of Commercial Management, Islamic Azad University, Electronic Branch, Tehran, Iran \\ ${ }^{3}$ Department of Information and Technology of Management, Electronic Branch, Islamic Azad University, Tehran, Iran \\ ${ }^{4}$ Department of Culture of Management, Science and Research Branch, Islamic Azad University, Tehran, Iran \\ ${ }^{5}$ Department of Mine Engineering, Bahonar, Kerman University, Kerman, Iran
}

\section{Email address:}

doshmanziari@gmail.com (E. D. Ziari), Kazemi.2013@yahoo.com (E. Kazemi), Bezad.af@gmail.com (B. Mirafshar), shahrmadar@gmail.com (A. Rashidi),pourahad@tehran.ir (V. Pourahad)

\section{To cite this article:}

Esfandiar Doshman Ziari, Ebrahim Kazemi, Behdad Mirafshar, Amir Rashidi, Vahideh Pourahad. Identifying and Ranking the Factors Affecting Honoring Customers in the Metropolitan Municipalities - Case Study of Tehran Municipality. International Journal of Law and Society. Vol. 1, No. 2, 2018, pp. 72-76. doi: 10.11648/j.ijls.20180102.13

Received: November 5, 2017; Accepted: November 20, 2017; Published: January 19, 2018

\begin{abstract}
The study is aimed to determine effective factors in respecting to clients by municipality's metropolitan authorities and grouping them into two groups of staff and city management organization to form the first step of the process on this basis. The research methodology based on conceptual model and on the thematic literature and the research carried out through 34 factors initially in two sections of staff and organization group by registration of the main variables and related data in the software, 306 regulatory questionnaires in Likert spectrum the correct data was initiated and ready to conformity factor analysis. The first output is the index value of the Bartlett test statistic equal to 0.882 (close to number 1) which shows the number of samples (in this example number of respondents) is sufficient for factor analysis. Also, sig value of Bartlett's test is less than $5 \%$, which indicates that the factor analysis is appropriate for identifying the structure, factorial model. The number of variables is reduced from 34 to 30 based on final subscription value (less than 0.5). As a result, the final variables affecting respect on client by metropolitan municipality according to the proposed model are divided into 17 variables in the organization main factor group and 13 variables in employees factor group.
\end{abstract}

Keywords: Municipality Service Receivers, Satisfaction of Clients, Employee Level Factors, Organization Level Factors, Urban Management

\section{Introduction}

Tehran municipality announced the client's respect plan considering the purposes such as: improving the citizen's satisfaction and client's satisfaction level with Tehran municipality by securing sufficient condition to provide the services (facilitation in the affairs, speed and accuracy in dealing with issues, appropriate behavior and respecting customers) and improving communication between staff and clients in all subsidiaries (deputies, all the 22 regions, headquarters, departments and subsidiaries nearly to 60 units) and all places, Tehran E-services offices, local cultural and social community centers over 374 centers and other sports and cultural complexes, in such a way that the priority of the plan was as follows: departments in terms of number and volume of the clients, in service affairs proportional to clients' satisfaction with the manner of services and how to track and deal with clients affairs including elders, veterans, disable, weak and other people, respectively. The plan has distinct administrative processes and informational and educational mechanisms [3].

Since any executive plan in the administrative systems 
requires an operational model to be effective and efficient, so the process of improving the respect plan cycle is imagined as the following figure.

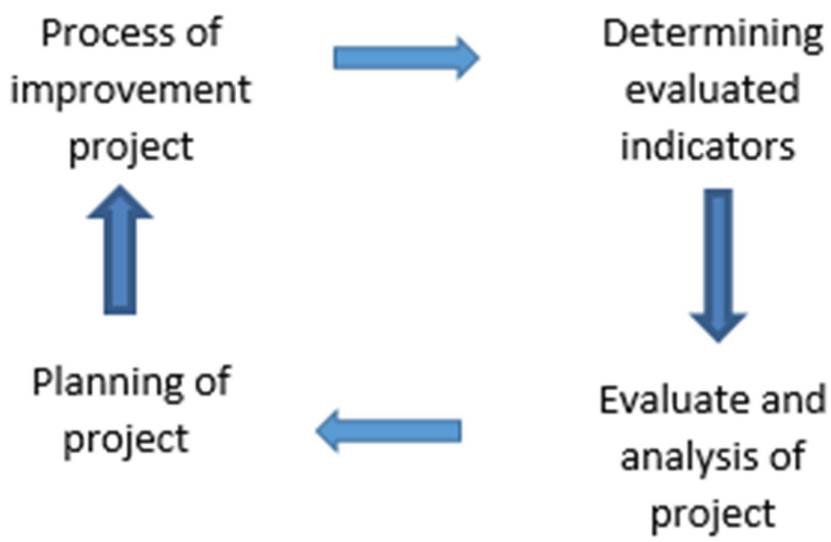

Figure 1. Honoring customer's management process.

Establishment of improving management of respect plan cycle leads the plan promotion as a permanent process, and road ahead and the necessary contexts will be made. After the execution of each step the plan have to be evaluated in the headquarters of urban management department, subsequently, improvement plans at different levels be scheduled and the continuous path of the respect improvement will be remained [4].

The main objective of the study is also to determine and group the effective factors of client's respect plan in urban management organization, following that each group is divided into subset indexes, and each index will be ranked according to the priority in a set of each rating groups and finally the weight of each major group of respect plan will be determined in order to senior directors of the organization would plan and approve the services according to general goals of the respect plan for citizenship based on these groups and annual coded plan indicators.

On the other hand, to clarify the affairs and document the service delivery processes for citizens in citizenship area and employees of the organization, the researched factors play a key role. So that each of the beneficiaries of the respect plan with forms and administrative checklists would evaluate and control the associated components to resolve potential problems during implementation. The progression of study goals such as methodology of statistical society is based on the respect plan for metropolitan municipality which includes, specifically, affecting factors on the clients' and peoples' respect plan, executive committee for Tehran municipality. Factors identification and ranking them in specific groups to evaluate the respect plan's performance and other beneficiary systems such as bonus, discipline and training are effective in this regard [10].

Tehran municipality as one of the largest social institutions benefiting from advantage of high volume of public demand besides maintaining its legal duties, with the ability to focus on establishing appropriate platform using advertising tool and mutual communication will be able to create trust between municipal staff and citizens and other social institutes, in such a way it makes the respect culture development, and it will protect the dignity and self-esteem of man based on religious democracy in the society. Therefore, the committee for the client's respect plan and client's satisfaction based on its social responsibility took action toward the relationship between Tehran municipality employees and honorable clients regarding to more interaction with their participation in the urban affairs management on the basis of increased clients' satisfaction in the health care, by setting up study and research workgroups, and the committee began its activities after conducting the necessary studies on the respect plan execution with codified programs in Tehran municipality. On the implementation path of the client's respect plan, improvement and modification of the optimal service delivery methods to people, an appropriate situation with a scientific look at different dimensions of the plan and science studies to achieve the transcendental goals that is speed, precision, accuracy and trust in honest service to respected citizens of the capital was paved. Tehran municipality has made more citizen participation in social activities by setting up executive committees in all of subsidiaries in the social and cultural activities development by creating core region plans, councils, electronic services offices, public-based supervisory council (1888 site), urban management center (137 Site), establishing notification center and client guide and alike. On the other hand, a comprehensive instruction was put into operation for face to face meetings in 2015 which in some parts included plan execution process, clarification and documentation of the service delivery to citizens, precise, comprehensive and transparent notification to people on the manner of service delivery, establishing notification center and client guide, improvement and modification of service delivery methods to citizens, supervision on employee's good behavior in subsidiaries before the clients, survey, employee opinion poll together with creation of an appropriate space, welfare services and work place organization [18].

Since, the respect plan originally leads to client's satisfaction, so, measuring the client's satisfaction regarding the urban management service through identification of measurement criteria and rating them is the main subject of the study, hereby it would be added to the plan effectiveness at the first place, in co-measurement criteria, the municipalities would calculate the achievement rate of the expected goals in respect plan to make the corrective actions in the improvement cycle of urban management's administrative structure be scheduled at the second place.

Therefore, according to the contents herein, the main subject of the research is:

Which factors could be effective in respecting toward the clients of municipalities?

\section{Materials and Methods}

The study from purpose, type and method point of view is 
practical, analytical and surveying, respectively. Using confirmatory factor analysis technic, the study has been drawn up based on 5-step executive algorithm design.

In this research library studies such as wide range of the books, journals, theses, as well as search in prestigious sits has been exploited which in the same field a questionnaire has been prepared in two general and specialized sections of five-point Likert scale for factor analysis tests and to make a pair comparison through software according to well-known researchers and faculty members that were pointed in theoretical principals. The questionnaire was designed in such a way that influential factors based on available theories are ready to share and rate by respondents. In addition, each respondent is also able to add or even modify some of the relevant factors to the questionnaire [19].

The statistical population of the study consists of 1500 subjects including directors, contractor, contractual and tenured employee of Tehran municipality together with citizens of Tehran in service delivery centers that were sampled at the respect plan centers in different regions of Tehran city.

For sampling and estimating the sample size, the computational method of the Charles Cochran equation 306 subjects among the respect plan members at the level of 22 regions, organizations and subsidiaries, talent experts plus some of the managers involved in the plan were elected which the inclusion criteria for these respondents were job experience over 6 years and having bachelor's degree or higher. Software is used in factor analysis and correlation test of variables which are naturally implemented and analyzed by the software depend on type of the process based on research's executive model, the data obtained from questionnaire in database. The number of testable variables are 34 defined variables of people's respect factors and client's satisfaction in the level of Tehran municipality service centers in two sections of employees and organization, and analytical software processing includes 5 input and output steps [16].

\section{Results and Discussion}

In the process of factor analysis, it should be ensure that the available date could be used for analysis. On the other hand, whether the number of date needed for factor analysis is appropriate not? For this purpose, the KMO index and the Bartlett test are used.

The index is in the rage of 0 to 1 . If the value of the index is close to one, the data are appropriate for factor analysis and otherwise, less than 0.6 usually is less appropriate for factor analysis in given data.

Initially according to the past research, 34 effective factors on metropolitan client's respect has been identified which are subjected to Bartlett test.

The first output according to the following figure shows the KMO index value, the Bartlett test statistic (which is a sequence of the Chi-square statistic), the degree of freedom, and the sig test statistic, respectively. Since the KMO index is
0.882 (close to one), the number of samples (in this example is the number of respondents) is sufficient for factor analysis.

Also, the sig value of Bartlett's test is less than $5 \%$, which indicates that the factor analysis is appropriate to identify the structure, factor model.

Table 1. Bartlett Test.

\begin{tabular}{ll}
\hline K.M.O measure of sampling adequacy & 0.882 \\
Bartlett's test (Chi-square) & 6626.519 \\
Df & 171 \\
Sig & .000 \\
\hline
\end{tabular}

The second output gives the extraction point.

The higher the extraction value, the better extraction values show the variables. If each extraction value is less than 0.5 , then that factor is excluded from the total existing values. Given the results, the output of software, excluded values from the analysis (ATM, WC, Ethical charter, suggestion box) are stopped due to being lower than final value (less than 0.5) in calculations and removed from the variable list. In a word, the number of initial variables are reduced from 34 to 30 . Indeed, excluded values from analysis are the factors that their presence doesn't explain much of variance.

In order to test the final question of the research, what are the ratios of effective factors on client's respect plan in country's metropolitan municipalities and are placed in what rank?

The third output of the software shows the remaining variables cycle over the main factors of employees and the organization which are rated according to variance variation respect to the factors. This is the feature of varimax rotation which distributes the variations among factors uniformly and makes to create this table.

Table 2. Component's rotated variables.

\begin{tabular}{|c|c|c|c|}
\hline raw & variables & $\begin{array}{l}\text { factors of } \\
\text { employees }\end{array}$ & $\begin{array}{l}\text { factors of } \\
\text { organization }\end{array}$ \\
\hline 1 & $\begin{array}{l}\text { Installing of the officers information } \\
\text { panel }\end{array}$ & 0.13 & 0.65 \\
\hline 2 & $\begin{array}{l}\text { presenting of the brochure of } \\
\text { guidebook }\end{array}$ & 0.34 & 0.78 \\
\hline 3 & establishing of answering machine & 0.23 & 0.54 \\
\hline 4 & Creating of website & -0.31 & 0.91 \\
\hline 5 & $\begin{array}{l}\text { Establishing of services and guidance } \\
\text { cabin }\end{array}$ & 0.19 & 0.53 \\
\hline 6 & notification panel & -0.29 & 0.56 \\
\hline 7 & Good employee behavior & 0.94 & 0.13 \\
\hline 8 & Accuracy and speed of operation & 0.78 & -0.36 \\
\hline 9 & Effective relationship customer & 0.84 & 0.39 \\
\hline 10 & Level of mastery and job awareness & 0.79 & 0.28 \\
\hline 11 & Observing of the laws and regulations & 0.59 & 0.17 \\
\hline 12 & Observing of the justice and equality & 0.91 & -0.24 \\
\hline 13 & Managing of effective time & 0.88 & 0.39 \\
\hline 14 & Professional responsibility & 0.71 & 0.11 \\
\hline 15 & Controlling of stress & 0.96 & 0.39 \\
\hline 16 & Power of responsiveness & 0.72 & 0.13 \\
\hline 17 & Organizing and dressing of office & 0.63 & 0.44 \\
\hline 18 & Suitable office space & 0.49 & 0.54 \\
\hline 19 & Suitable office equipment & 0.38 & 0.61 \\
\hline 20 & Suitable organization establishment & 0.26 & 0.92 \\
\hline 21 & Suitable welfare facilities & 0.17 & 0.86 \\
\hline
\end{tabular}




\begin{tabular}{|c|c|c|c|}
\hline raw & variables & $\begin{array}{l}\text { factors of } \\
\text { employees }\end{array}$ & $\begin{array}{l}\text { factors of } \\
\text { organization }\end{array}$ \\
\hline 22 & Establishing office automation & 0.28 & 0.74 \\
\hline 23 & $\begin{array}{l}\text { Suitable form design and to be logic of } \\
\text { document }\end{array}$ & 0.18 & 0.81 \\
\hline 24 & $\begin{array}{l}\text { surveying and analyzing of costumer } \\
\text { opinions }\end{array}$ & 0.37 & 0.62 \\
\hline 25 & $\begin{array}{l}\text { determining of the suitable cost of } \\
\text { service }\end{array}$ & -0.49 & 0.55 \\
\hline 26 & $\begin{array}{l}\text { employee encouragement and } \\
\text { punishment }\end{array}$ & 0.48 & 0.64 \\
\hline 27 & $\begin{array}{l}\text { handling of complaints and announcing } \\
\text { the results }\end{array}$ & 0.49 & 0.58 \\
\hline 28 & improving and correcting of methods & 0.23 & 0.86 \\
\hline 29 & training of staff & 0.54 & 0.47 \\
\hline 30 & reducing of time working & 0.51 & 0.49 \\
\hline
\end{tabular}

Bulletin Board Operator installation; brochures or manuals provision; interactive voice response placement; internet sites creation; instructive and service point's establishment; bulletin; employee good behavior; Accuracy and speed; effective communication with the client; proficiency and job awareness; laws and regulations observance; justice and equity observance; effective time management; professional responsibility; stress control; responsiveness; workplace organization and discipline; appropriate office space; appropriate office equipment; appropriate deployment of organization; appropriate accommodation; administrative automation deployment; appropriate form design; document's rationality; surveying and analyzing customer's opinions; appropriate service cost tariff determination; employee motivation and discipline; complaint handling and the results announcement; improvement and modification methods; employees training; working time reduction.

The values of the above table show the component's rotated matrix respect to the two main factors of employees and organization in client's respect. The greater the magnitude of the absolute value of the coefficients, the related factor has greater role in total variations (variance).

Indeed, this table shows how 30 influential variables in municipality client's respect are divided into two employees and organization with which rank, for example employees training in employees' factor is ranked 0.54 and that of in organization's factor is ranked $0.47 \mathrm{rank}$, this means that the training is associated with employee's factor and plays a role in the respect plan.

\section{Conclusion}

Since the municipalities are at the core of social and urban management delivery services to citizens, so it should pay attention to people's respect and their satisfaction with service delivery besides service planning, indicating their social responsibility to citizens. It was attempted these factors being identified in the factors related to employees and organization in urban management organization, therefore the confirmative factor analysis was used in the research plan, it was determined given the results and software output at the first step.

The fact that 34 initial variables are related in terms of meaning and structure, so in the next step, 4 variables were excluded from the study due to the ranking less than 0.5 , of the remaining 30 variables they were ranked in two employees and organization sections.

Consequently, the effective final variables in client's respect at metropolitan municipalities are characterized and approved in the above table. So that out of 30 remaining variables in the study, 17 variables were divided in the organization's main factor group and 13 variables in employees factor group.

\section{References}

[1] Ang Liu, Stephen. Lu, Wei Wei. (2014).' “A New Framework of Ideation-oriented Customer Involvement". Procedia CIRP Publication, Journal of Elsevier, Volume 21, 2014, Pages 521526.

[2] Abtahi, h. (2004), "Improvement of human resources managemeent", Iran Industrial Development and Renovation Organization. Tehran.

[3] Amani, n. (2009). "A Comprehensive Book of honoring customers in the municipality of Tehran". Alesamad Publication, Tehran. Iran.

[4] Azimi, a. (2016). "Municipality jihad management and promotion of productivity with the aim of sustainable urban economy", Partoe vaghe Publication. Tehran. Iran.

[5] Aydın, Cengiz Hakan Tasci, Deniz. (2005). "Measuring Readiness for e-Learning": Reflections from an Emerging Country. Educational Technology \& Society, 8 (4), 244-257.

[6] Anderson, t. (2005), "Dissatisfaction with public service" firth published; Open University press, p. 35.

[7] Baber, W. R., Gore, A. K., Rich, K. T., \& Zhang, J. X. (2013). Accounting restatements, governance and municipal debt financing. Journal of Accounting and Economics, 56(2), 212227.

[8] Bergstresser, D., Cohen, R., \& Shenai, S. (2013). Demographic fractionalization and the municipal bond market. Municipal Finance Journal, 34(3), 1-38.

[9] Cuny, C.(2016). Voluntary disclosure incentives: Evidence from the municipal bond market. Journal of Accounting and Economics, 62(1), 87-102.

[10] Campello, M. Gao, J. (2017). "Customer concentration and loan contract terms". Journal of Elsevier, Volume 123, Issue 1, Pages 108-136.

[11] Dasgupta, C. Pungaliya, E. (2015). "Reputation and loan contract terms: the role of principal customers". Jouranal of Review of Finance, 14 (2015), pp. 1-33.

[12] Hawari, M. (2012). Automated serv ice quality as a predictor of customers' commitment: A practical study within the UAE retail banking context. Asia Pacific Journal of Marketing and Logistics, Vol. 23, pp. 346-366.

[13] Kazemi, m. Abaspour, m. Asgaripour, h. (2013). "Identifying and defining the factors influencing customer reliance by using hierarchical analysis techniques". Conference on Challenges and Solutions Management, Shiraz, Iran. 
[14] Lee, C. K. and Song, H. J. and Lee, H. M. and Lee, S. and Bernhard, B. J. (2015). "The impact of CSR on casino employees" organizational trust, job satisfaction, and customer orientation: An empirical examination of responsible gambling strategies. International Journal of Hospitality Management, Vol. 33, pp. 406-415.

[15] Liang, R. D. and Zhang, J. S. (2014). The effect of service interaction orientation on customer satisfaction and behavioral intention: The moderating effect of dining frequency. Asia Pacific Journal of Marketing and Logistics, Vol. 24, pp. 153170.

[16] Momeni, m. Ghayomi, f. (2008). "Statistical analysis using software". new Book Publication. Volume 2. Tehran. Iran.

[17] Mohamadi, a. (2003). "Customer Orientation management system”. rasa publication, Volume 4. Tehran, Iran.
[18] Rachelle, J. Shannahan, Alan J. Bush, Kirby L. J. (2017). "How salesperson perceptions of customers' pro-social behaviors help drive salesperson performance". Industrial Marketing Management Publication. Journal of Elsevier, Volume 62, April 2017, Pages 36-50.

[19] Sowa, P. Bargiel, J. (2016). "Ways of Improving the Reliability of Supply of Selected Important Municipal Customers in Municipalities". Journal of Acta Energetica, Vol 1, pages 93-97.

[20] Schultz, P. (2013). The market for new issues of municipal bonds: The roles of transparency and limited access to retail investors. Journal of Financial Economics, 106(3), 492-512.

[21] Syverson, C. (2004). "Productivity Substitutability \& Productivity dispersion", Review of Economics and Statistics, p 534, London. 